\title{
Measuring health in pulmonary hypertension: emphasising the right end-point?
}

\author{
Mardi Gomberg-Maitland ${ }^{1}$ and Hubert Chen $^{2}$
}

Affiliations: ${ }^{~}$ University of Chicago Medicine, University of Chicago Medicine, Chicago, IL, and ${ }^{2}$ Respiratory and Allergic Diseases, Genetech, Inc., San Francisco, CA, USA.

Correspondence: M. Gomberg-Maitland, Pulmonary Hypertension Center, University of Chicago, 5841 S Maryland Ave, MC 5403, L08, Chicago, IL 60631, USA. E-mail: mgomberglabsd.uchicago.edu

0

@ERSpublications

emPHasis-10 addresses the unmet need for disease-specific quality of life instruments for pulmonary hypertension http://ow.ly/tdPDV

Pulmonary hypertension $(\mathrm{PH})$ is a condition deriving from multiple aetiologies with the recent focus on Group 1 pulmonary arterial hypertension (PAH) and Group 4 chronic thromboembolic pulmonary hypertension (CTEPH) largely due to the surge of understanding in pathophysiology and resultant treatments available [1]. Both are a disease of the pulmonary circulation that is characterised by a progressive rise in pulmonary artery pressure (PAP) and pulmonary vascular resistance (PVR), with limited dysfunction of the left ventricle [2]. Symptoms manifest as patients' lose the ability to augment their cardiac output in the face of a fixed vascular resistance [3]. In addition, anxiety and depression disorders are highly prevalent in PAH and CTEPH patients and correlate with the patients' sense of wellness [4]. However, despite therapeutic options and overall improved outcomes, life expectancy is shortened $[5,6]$ and patients must face the myriad of issues that go along with a chronic debilitating fatal disease [7-9].

The definition of "good health" is not just the absence of disease but also incorporates emotional and physical security, a sense of contentment. The World Health Organization first formally acknowledged this concept in the 1952 proceedings, embracing the importance of "quality of life" (QoL) [10]. Health-related QoL (HRQoL) is a composite of physical, psychological and social domains of health seen as distinct qualities influenced by a person's perceptions or expectations [11]. It is important to realise that HRQoL has multiple components, a multidimensionality, representing numerous states of health, distinct from survival time [11]. Standardised metrics have been developed to quantitatively assess this abstract conceptualisation of well-being. The quantitative science of questionnaire development, however, needs to be balanced by the practicality of any measure. In practice, questionnaires need to be easily administered and scored. In addition, understanding what level of change is considered clinically meaningful is of critical importance. Although HRQoL outcomes usually correlate with standard objective measures at the population level, the extent to which a change in the "average score" can be translated to any given individual is often met with scepticism [12].

In this issue of the European Respiratory Journal, YORKE et al. [13] introduce a new PH-specific questionnaire, the emPHasis-10, a 10 item survey assessing "how PH affects" the patient's life. This study addresses an important, unmet need in the field of $\mathrm{PH}$, for which disease-specific instruments are limited. To date, the only instrument developed specifically for PH is the Cambridge Pulmonary Hypertension Outcome Review (CAMPHOR) [14-18]. Despite international validation, the CAMPHOR has certain attributes that have limited its widespread adoption. It is comprised of three separate scales, each of which

Received: Jan 022014 | Accepted after revision: Jan 082014

Conflict of interest: Disclosures can be found alongside the online version of this article at www.erj.ersjournals.com

Copyright @ERS 2014 
has its own response options, scoring and subdomains. While its measurement properties were carefully examined during the development process, its "real-world" performance in the hands of external investigators remains to be established. A recent study suggests that the CAMPHOR is predictive of clinical deterioration at diagnosis but is not predictive over time [19]. The development of a new instrument that can be quickly administered in a clinic setting and yields a single score has appeal, and provides researchers with greater choice in terms of study measures.

Although there is no universally accepted method for designing questionnaires, the overall approach used in the development of the emPHasis-10 follows the general practices commonly utilised by those in the field today; that is, qualitative interviewing to generate item content, cognitive testing of proposed items, item reduction, followed by an assessment of reliability, repeatability and concurrent validity. Moreover, the authors also employed modern psychometric techniques, specifically Rasch analysis, to assess item "fit" and "difficulty" with respect to the "ability" of the surveyed population. In general, development of the emPHasis-10 appears consistent with the basic principles outlined by the US Food and Drug Administration Guidance to Industry for Patient-Reported Outcomes [20], but ultimately its acceptability as a regulatory end-point in clinical trials remains to be determined.

No questionnaire is without limitations. Some behavioural researchers may argue that the breadth and depth of a patient's QoL cannot simply be reduced down to a single number derived from 10 questions. HRQoL, by definition, is inherently multidimensional, but conventional and modern psychometric techniques used to perform item reduction assume a one-dimensional construct. Such approaches can result in an instrument that has optimised statistical properties, but that does not guarantee an accurate/ valid assessment of the end-point it was intended to measure. Plus, with ongoing debate about current $\mathrm{PH}$ end-points and biomarkers as "true" surrogates of the disease for clinical practice and clinical trials, it is less clear how to assess the value of PH HRQoL with these comparators. In the debate between idealism and pragmatism, the developers of the emPHasis-10 have chosen the latter path, which some may argue is reductionist, but is reasonable given their goal of designing a tool that can be feasibly implemented within the demands of today's busy medical practice.

Although further work is required to determine its value in routine clinical practice, the emPHasis-10 holds promise as a new disease-specific measure for $\mathrm{PH}$. Unlike other proprietary instruments, for which use can be restricted, development of the emPHasis-10 was funded by the Pulmonary Hypertension Association UK; consequently, "open access" to the instrument will be provided to clinical and academic communities. One potential advantage of such an approach will be not only to enhance the adoption this new instrument, but also to facilitate external validation of its value in clinical practice, and perhaps in clinical trials as well. Even if regulatory authorities never accept HRQoL as a primary end-point, payers are increasingly demanding it. As healthcare resources continue to become more constrained, costly new therapies and devices must demonstrate their value as agents of "good health". For PH specifically, satisfaction must be proved beyond just walking distance alone. With its emphasis on HRQoL in PH, emPHasis-10 may fulfil this role.

\section{References}

1 Simonneau G, Robbins IM, Beghetti M, et al. Updated clinical classification of pulmonary hypertension. J Am Coll Cardiol 2009; 54: Suppl. 1, S43-S54.

2 Badesch DB, Champion HC, Sanchez MA, et al. Diagnosis and assessment of pulmonary arterial hypertension. J Am Coll Cardiol 2009; 54: Suppl. 1, S55-S66.

3 Galiè N, Hoeper MM, Humbert M, et al. Guidelines for the diagnosis and treatment of pulmonary hypertension: the Task Force for the Diagnosis and Treatment of Pulmonary Hypertension of the European Society of Cardiology (ESC) and the European Respiratory Society (ERS), endorsed by the International Society of Heart and Lung Transplantation (ISHLT). Eur Heart J 2009; 30: 2493-2537.

4 Harzheim D, Klose H, Pinado FP, et al. Anxiety and depression disorders in patients with pulmonary arterial hypertension and chronic thromboembolic pulmonary hypertension. Respir Res 2013; 14: 104.

5 Gomberg-Maitland M, Dufton C, Oudiz RJ, et al. Compelling evidence of long-term outcomes in pulmonary arterial hypertension? A clinical perspective. J Am Coll Cardiol 2011; 57: 1053-1061.

6 Ling Y, Johnson MK, Kiely DG, et al. Changing demographics, epidemiology, and survival of incident pulmonary arterial hypertension: results from the pulmonary hypertension registry of the United Kingdom and Ireland. Am J Respir Crit Care Med 2012; 186: 790-796.

7 Cenedese E, Speich R, Dorschner L, et al. Measurement of quality of life in pulmonary hypertension and its significance. Eur Respir J 2006; 28: 808-815.

8 Löwe B, Gräfe K, Ufer C, et al. Anxiety and depression in patients with pulmonary hypertension. Psychosom Med 2004; 66: 831-836.

9 McDonough A, Matura LA, Carroll DL. Symptom experience of pulmonary arterial hypertension patients. Clin Nurs Res 2011; 20: 120-134.

10 World Health Organization. Chronicle of the World Health Organization Vol. 6, No.7-8. Geneva, World Health Organization 1952. http://whqlibdoc.who.int/chronicle/1952/WHO_CHRON_1952_6(7-8).pdf.

11 Testa MA, Simonson DC. Assessment of quality-of-life outcomes. N Engl J Med 1996; 334: 835-840. 
McKenna SP, Doughty N, Meads DM, et al. The Cambridge Pulmonary Hypertension Outcome Review (CAMPHOR): a measure of health-related quality of life and quality of life for patients with pulmonary hypertension. Qual Life Res 2006; 15: 103-115.

15 Chua R, Keogh AM, Byth K, et al. Comparison and validation of three measures of quality of life in patients with pulmonary hypertension. Intern Med J 2006; 36: 705-710.

16 Gomberg-Maitland M, Thenappan T, Rizvi K, et al. United States validation of the Cambridge Pulmonary Hypertension Outcome Review (CAMPHOR). J Heart Lung Transplant 2008; 27: 124-130.

17 Ganderton L, Jenkins S, McKenna SP, et al. Validation of the Cambridge Pulmonary Hypertension Outcome Review (CAMPHOR) for the Australian and New Zealand population. Respirology 2011; 16: 1235-1240.

18 Cima K, Twiss J, Speich R, et al. The German adaptation of the Cambridge Pulmonary Hypertension Outcome Review (CAMPHOR). Health Qual Life Outcomes 2012; 10: 110

19 McCabe C, Bennett M, Doughty N, et al. Patient-reported outcomes assessed by the CAMPHOR questionnaire predict clinical deterioration in idiopathic pulmonary arterial hypertension and chronic thromboembolic pulmonary hypertension. Chest 2013; 144: 522-530.

20 U.S. Department of Health and Human Services Food and Drug Administration, Center for Drug Evaluation and Research (CDER), Center for Biologics Evaluation and Research (CBER), Center for Devices and Radiological Health (CDRH). Guidance for Industry Patient-Reported Outcome Measures: Use in Medical Product Development to Support Labeling Claims. U.S. Department of Health and Human Services Food and Drug Administration, 2009. www.fda.gov/downloads/Drugs/GuidanceComplianceRegulatoryInformation/Guidances/ UCM193282.pdf Date last accessed: September 6, 2013. 